\title{
Educação antirracista nas universidades públicas: novos sujeitos, velhas estruturas e demandas além das cotas
}

Maria Raimunda Penha Soares ${ }^{1}$

Rebeca Ribeiro da Silva²

\section{Resumo}

Este artigo visa problematizar a crescente inserção de negros(as) nas universidades públicas e uma estrutura acadêmica que está em descompasso com uma educação antirracista. Buscamos evidenciar a importância da extensão universitária voltada para a questão étnico-racial, na transformação do espaço universitário; e destacamos as contribuições do projeto de extensão Questões étnico-raciais e vivências em cultura afro-brasileira na autoafirmação de negros(as) dentro e fora do Campus da Universidade Federal Fluminense (UFF) em Rio das Ostras. Por fim, o artigo apresenta a indissociabilidade entre ensino, pesquisa e extensão para que a universidade também se consolide como um espaço de combate ao racismo.

\author{
Palavras-chave \\ Universidade; Extensão; Antirracismo.
}

Antiracist education in public universities: new subjects, old structures and demands beyond quotas

\begin{abstract}
This article problematizes the growing insertion of blacks in public universities and an academic structure that is out of step with an antiracist education. We seek to emphasize the social importance of university extension, focused on racial issue, to the transformation of academical environment; we highlight the contributions of the extension project Questões étnico-raciais e vivências em cultura afro-brasileira to the organization and self-affirmation of blacks inside or outside Universidade Federal Fluminense (UFF) in Rio das Ostras. Finally, the article presents the indispensable connection between teaching, research and extension so university can also consolidate itself as a combating racism space.
\end{abstract}

\section{Keywords}

University; Extension; Antiracism.

Artigo recebido: novembro de 2020

Artigo aprovado: dezembro de 2020 


\section{Introdução}

Neste artigo, partimos da premissa de que as universidades públicas não devem ser reduzidas a espaços de produção de profissionais aptos a atuarem no mercado, mas sim, um locus privilegiado de construção de conhecimento crítico, de ciência, de tecnologia e de instrumentos científicos que tornem possível a transformação da sociedade. Dessa forma, pensar a universidade é pensá-la politicamente. Para além de formar sujeitos para o mundo profissional, essas instituições, portanto, têm o papel de contribuir com o pensamento crítico que incida diretamente na transformação da sociedade. Sob essa perspectiva, toda formação universitária deveria ser crítica por princípio, de modo que esse aspecto só se efetiva como tal se incorporarmos o debate da questão étnico-racial na sua centralidade, pois entendemos que ele é fundamento da constituição das relações sociais contemporâneas e, por isso, estrutural na conformação da questão social brasileira ${ }^{3}$.

Quando se pergunta, então, qual é o papel social e político da universidade pública, entende-se que a resposta se encontra nessa articulação direta com setores populares, periféricos e subalternizados da sociedade, por meio de programas e projetos de pesquisa e extensão "realizados junto a grupos sociais e movimentos populares das localidades onde a universidade se insere" (SOARES et al., 2018, p. 537).

O projeto de extensão Questões étnico-raciais e vivências em cultura afro-brasileira surge com essa perspectiva em 2011, no Campus da Universidade Federal Fluminense (UFF) em Rio das Ostras (RJ). A iniciativa em questão tem como objetivo realizar vivências em comunidades quilombolas do estado do Rio de Janeiro, que incluam datas comemorativas (relacionadas a expressões da cultura afro-brasileira) e ações político-organizativas; bem como promover estudos da questão racial no Brasil; realizar atividades acadêmico-científıcas que debatam esse tema no país; e organizar a Semana da Cultura Afro-brasileira em novembro ou dezembro de cada ano. 
Apresentaremos, neste artigo, a importância social deste projeto no âmbito da UFF, na cidade de Rio das Ostras e na região, como uma proposta antirracista, debatendo o papel da extensão universitária e sua interface com a pesquisa e o ensino. Além da introdução e das considerações finais, nosso trabalho está composto por quatro itens, nos quais discutimos sobre a atualidade da inserção de negros(as) nas universidades brasileiras, assim como a relação entre essas instituições e a questão racial; a Semana de Cultura Afro-brasileira e sobre ser negro na educação superior. Alguns depoimentos que constam neste artigo foram levantados a partir de pesquisa ${ }^{4}$ feita para a atividade UFF nas Praças, realizada no mês de maio de 2019, em diversos pontos da cidade.

Por fim, ressaltamos o desafio que a política de cotas nos propõe quando possibilita a inserção de negros e negras nas universidades, qual seja, o de transformar as estruturas de produção de conhecimento dentro e a partir desse espaço, desafıo de problematizar a colonialidade do poder e do saber (QUIJANO, 2000) e o racismo institucional.

\section{O acesso de estudantes negros à universidade brasileira e a permanência deles a partir das cotas}

Decorridas aproximadamente duas décadas da aprovação das primeiras legislações sobre a inserção de negros(as) em universidades públicas via cotas, podemos identificar que avançamos, mas os desafios ainda são grandes. Considera-se que as conquistas decorrem das mobilizações dos movimentos negros e da articulação de coletivos populares em torno da efetivação das cotas para ingresso da juventude negra nas instituições de ensino superior.

O perfil dos estudantes de universidades públicas federais mudou nos últimos anos (ANDIFES, 2019). Segundo dados da Andifes (2019), 51,2\% da população pesquisada nas Instituições Federais de Ensino Superior (Ifes) é negra. Os resultados da pesquisa em questão apontam que, em 15 anos, as ações afırmativas foram responsáveis pela 
elevação do número de estudantes pretos(as) e pardos(as) de 160.527 para 613.826, com variação de 282\% (ANDIFES, 2019) ${ }^{5}$.

A pesquisa evidencia, por outro lado, uma das questões que se encontra no centro das dificuldades de permanência desses estudantes no ensino superior público, que são suas condições financeiras. Mais da metade desses alunos vive em famílias com renda per capta de até um salário mínimo (ANDIFES, 2019). Trata-se, como os dados indicam, não só de estudantes negros(as), mas de baixa renda, portanto, de trabalhadores e filhos de trabalhadores que demandam não só a entrada nas universidades, mas também políticas de assistência estudantil efetivas (GONÇALVES; AMBAR, 2015).

Temos, ainda, de observar que a composição dos quadros de docência e de gestão das universidades não reflete o impacto das cotas na educação superior, pois esses são compostos majoritariamente de pessoas brancas. Pesquisa do Instituto Nacional de Estudos e Pesquisas Educacionais Anísio Teixeira (Inep) indica que a maioria dos docentes do ensino superior do país é branca, em torno de 52,9\%, sendo que professores negros representam apenas $16 \%$ desses profissionais (INEP, 2019). Em se tratando da pós-graduação, esses dados são ainda mais impactantes. Em análise da composição racial de docentes de todos os programas de mestrado e doutorado em Ciências Sociais creditados pela Capes, observou-se que $3 \%$ eram pretos; $12 \%$, pardos; e 77\%, brancos (BOLETIM OCS, 2018; 2020).

Por outro lado, não há dúvidas de que os debates dentro das universidades têm mudado e incorporado pautas acadêmicas, científıcas e políticas que advêm desses segmentos da classe trabalhadora que ingressaram nesse meio. A questão que apresentamos, entretanto, é se houve, de fato, mudanças estruturais nos espaços acadêmicos que possibilitassem que esses "novos sujeitos", que passaram a ingressar nesse universo, tivessem seus saberes, conhecimentos e culturas reconhecidos. Segundo Petronilha Silva (SILVA, 2003, p. 56-57), esse ponto continua sendo um desafıo e uma questão central nas univer- 
sidades, "admitir que os antigos escravizados africanos trouxeram consigo saberes, conhecimentos, tecnologias, práticas que lhes permitiram sobreviver e construir um outro povo", o que coloca as universidades diante de um desafio maior, que é “incorporá-los ao corpo de saberes que cabe, à universidade, preservar, divulgar, assumir como referências para novos estudos" (SILVA, 2003).

Neste cenário, de avanços e tensões, surgem projetos de pesquisa e extensão que, em diálogo indissociável com o ensino, têm proposto o entendimento e a produção de conhecimento sobre a realidade da população negra brasileira, em suas diversas dimensões, e a transformação de contextos opressivos e de reprodução de racismos e preconceitos dentro e fora das universidades.

\section{A universidade e a questão racial: rompendo muros e silenciamentos}

O Brasil é estruturalmente racista, e a prática do racismo se materializa em distintos espaços da vida social. Não seria diferente na educação; em particular, na universitária. Durante muito tempo, buscou-se negar o protagonismo negro nesse ambiente, fato que também se constitui em uma grande violência. Abdias Nascimento afırma que

O sistema educacional funciona como aparelhamento de controle nesta estrutura de discriminação cultural. Em todos os níveis do ensino brasileiro - primário, secundário, universitário - o elenco das matérias ensinadas, como se executasse o que havia previsto a frase de Silvio Romero, constitui um ritual da formalidade e da ostentação das salas da Europa e, mais recentemente, dos Estados Unidos. Se consciência é memória e futuro, quando e onde está a memória africana, parte inalienável da consciência brasileira, no currículo escolar? Onde e quando a história da África, o desenvolvimento de suas culturas e civilizações, as características do seu povo, foram ou são ensinadas nas escolas brasileiras? Ao contrário, quando há alguma referência ao africano ou negro, é no sentido de afastamento e da alienação da identidade negra. (NASCIMENTO, 2016, p. 113). 
O período pós-abolição é um importante referente para se pensar a estrutura de poder e o racismo institucional que atravessam os modelos de educação superior propostos e consolidados no Brasil. Os negros "saíram" da condição de objeto para a de problema (RAMOS, 1995), e é nesta última situação, e não na de sujeitos ou de cidadãos (no modelo liberal), que são tratados pelo Estado e pelas instituições públicas, incluindo as universidades.

Dessa forma, aos negros cabia o lugar de serem observados, estudados e analisados, objetos para o conhecimento científico. Foi assim que "entraram" no universo acadêmico. A universidade, portanto, era não só o terreno da branquitude (CONÇALVES; AMBAR, 2015), mas também o espaço científico que legitimou o lugar do negro como problema social. Para a solução do "problema do negro" (CONÇALVES; AMBAR, p. 205), é apontado o branqueamento da nação, um projeto político que implicava genocídio de corpos e de culturas (NASCIMENTO, 2016), que se inicia no período pós-abolição e ainda está em curso.

Para muitos negros, a universidade era e/ou é um espaço inatingível, e alcançá-lo demandava aproximar-se de uma brancura que era o único lugar/objetivo ao qual podiam chegar (FANON, 2008). É preciso lembrar que os poucos negros que cursavam a universidade ${ }^{6}$, e quando cursavam, em sua maioria, reproduziam as formas eurocêntricas de pensar seus semelhantes como objetos. Dessa forma, "clarear a raça passou também a fazer parte de um mecanismo de defesa para os não-brancos" (CONÇALVES; AMBAR, 2015, p. 205). Inseridos nessa realidade, homens e mulheres negros começam a usar outros adjetivos que se afastam minimamente da negritude, para definir sua raça como "pardo", "moreno claro ou escuro" ou, até mesmo, como "negros de alma branca". Sueli Carneiro (2011, p. 64) denuncia que

Aqui, aprendemos a não saber o que somos e, sobretudo, o que devemos querer ser. Temos sido ensinados a usar a miscigenação ou a mestiçagem como carta de alforria do estigma da negritude: um tom de pele mais claro, cabelos mais lisos ou um par de 
olhos verdes herdados de um ancestral europeu são suficientes para fazer alguém que descenda de negros se sentir pardo ou branco, ou ser "promovido" socialmente a essas categorias. E o acordo tácito é que todos façam de conta que acreditam.

Neste cenário controverso e complexo, negros e negras têm seu acesso aos direitos básicos, incluindo educação, negado. As políticas públicas que vão se consolidando no Brasil, a partir dos tensionamentos de classe, não contemplam as particularidades da população negra. Não obstante, considerando o acúmulo das lutas históricas e depois de intensas mobilizações dos movimentos negros, em especial, na década de 1990, foram instituídas as chamadas políticas afirmativas (a partir dos anos 2000), quando já se haviam passado mais de 100 anos do fim oficial da escravidão.

Nesse contexto, as políticas de cotas representaram uma possibilidade real de ingresso no ensino superior aos jovens negros da classe trabalhadora. Para além dos instrumentos de acesso, em termos quantitativos, dos negros e negras às universidades, devemos problematizar, como já indicamos acima, tanto as condições de permanência e formação desses futuros profissionais, quanto o modelo de produção de conhecimento que vigora hoje no espaço acadêmico.

A crítica à estrutura das universidades não visa apenas transformá-la em um lugar acolhedor aos negros, mas, de fato, repensar o que fundamenta a produção de conhecimento nesse espaço, que ainda reproduz a colonialidade do saber (QUIJANO, 2000). Importa considerar, a partir da realidade sócio-histórica e cultural desses sujeitos - negros, indígenas e quilombolas que agora ingressam no universo acadêmico - , quais epistemologias podem realmente ser referenciadas como necessárias para a construção de uma universidade popular, libertária e antirracista, com um papel fundamental na transformação da sociedade. Como Indica Petronilha Silva,

É importante ter claro, quando a universidade brasileira se propõe a adotar um plano de ações afirmativas, que não se en- 
contra tão somente buscando corrigir os erros de 500 anos de colonialismo, escravidão, extermínio de povos indígenas e negros, de tentativas de extinção de suas concepções, crenças, atitudes, conhecimentos mais peculiares. Está, isto sim, reconhecendo que, apesar dos pesares, muitos deles não foram extintos e precisam ser valorizados, reconhecidos não como exóticos, mas como indispensáveis para o fortalecimento político desses grupos, bem como político e acadêmico da universidade. (SILVA, 2003, p. 49).

Consideramos que, enquanto a colonialidade do saber (QUIJANO, 2000) funcionar como um instrumento legitimador de um modelo de capitalismo dependente, que tem nas contradições de classe e nas diferenças raciais, de gênero e sexo, seus fundamentos de expansão geopolítica e econômica, haverá a persistência de um modelo de universidade elitista, branqueado e eurocêntrico. O que deve ser demarcado, entretanto, é que os caminhos percorridos por intelectuais e militantes negros no mundo e no Brasil, que contestaram esse ideário de produção de conhecimento e de sistema de exploração e opressão; bem como a ação dos movimentos negros, de mulheres, de indígenas e de quilombolas e a entrada desses sujeitos nas universidades nos permitem disputar esse espaço com outras epistemologias, assumindo o caráter decolonial e antirracista e reafirmando outros modos de vida e cosmovisões que tragam, em sua organização, elementos anticapitalistas e contra coloniais (SANTOS, 2015).

\section{Semana de Cultura Afro-brasileira: por que um evento acadêmico e científico de protagonismo negro ainda causa desconforto na universidade?}

Apesar das mudanças visíveis no meio universitário quanto à inserção de negros e negras em diversos espaços antes quase que de exclusividade branca, temos que nos perguntar que mudanças estruturais ocorreram ou estão em curso para que, de fato, os corpos negros deixem de ser os matáveis, os estigmatizados, os excluídos, os vio- 
lados e os indesejáveis em uma sociedade que tem o racismo como elemento estruturante. Por outro lado, ainda se observam reações de espanto e incômodo com esses sujeitos ocupando um "espaço" que material e ideologicamente não foi pensado para eles.

Os estudantes negros que ingressam nas universidades, especialmente nas universidades públicas, por meio das cotas raciais, encontram uma estrutura acadêmico-científica que, apesar dos esforços e com exceções, ainda não está preparada adequadamente para recebê-los, pois sempre os tratou como objetos ou problemas. Dessa forma, transformar esse espaço sempre foi e continua sendo um desafio, não só aos negros e negras que nele ingressam e que por ele transitam, mas a qualquer um que se propõe a uma práxis efetivamente antirracista.

É preciso lembrar que a violência sofrida pelo povo negro é histórica e se expressa de formas diversas. Uma delas, que provoca efeitos muito perversos e dolorosos, é a constante tentativa de apagamento da memória cultural e identitária dessa população. Mais do que isso: a ideia é que negros e negras odeiam a si, seus traços e a sua cultura, entendendo que tudo aquilo que é belo deve ser associado ao branco (FANON, 2008). Esse processo tende a perpetuar o modelo de sociedade hoje vigente, que reproduz as desigualdades e continua encontrando espaço para se fortalecer.

Adentrar no universo acadêmico implica, em um primeiro momento, tensionar o lugar comum reservado ali para os negros: o de problema ou negro/tema (RAMOS, 1995). Por outro lado, implica também a construção de outro lugar, outra perspectiva que dialogue com elementos sócio-históricos apagados a ferro e fogo da história oficial e memória coletiva. É preciso, como nos indica Lélia Conzalez (2018), fazer emergir uma memória que revele o que a consciência, mesmo a consciência crítica, esconde.

Essa memória (CONZALEZ, 2018), que é histórica e coletiva, precisa, às vezes, emergir usando recursos não convencionais no meio acadêmico: a estética negra, a dança, a música, os tambores, as ex- 
pressões da cultura afro-brasileira, os símbolos e o questionamento de uma branquitude que se faz presente e visível em todos os espaços dentro da instituição; mas também os recursos usuais da academia, os estudos sistemáticos, a produção científica, as pesquisas e os debates dentro do meio universitário, sempre importantes para que se construa, de fato, um espaço plural e não excludente de ideias. Foi com essa perspectiva que realizamos a I Semana da Cultura Afro-brasileira no Campus da UFF em Rio das Ostras.

A realização do evento, em 2011, apresentou um desafio e trouxe à tona uma questão importante para o debate sobre a extensão universitária, motivada pelo impacto que as diversas ações promoveram. A proposta desse encontro inicial não era chocar ou trazer o debate estético como elemento central, entretanto foi estabelecido como objetivo promover uma mudança na "cara da universidade", de modo que os participantes fossem notados e que a discussão não se restringisse ao modo tradicional, em uma sala ou auditório, apenas com os interessados no tema ou com os que, de alguma forma, são impactados por ele.

A proposta era de que o campus soubesse que discutíamos a questão étnico-racial, mas, além disso, havia o objetivo de trazer, por meio das atividades, o público externo para dentro da universidade e integrá-lo à comunidade acadêmica: professores, técnicos, estudantes e servidores terceirizados, sendo a maioria negra neste último caso. Nossa escolha foi realizar as atividades (debates, palestras, algumas oficinas, rodas de jongo e capoeira) no hall de entrada do prédio do campus, de modo que a maioria do público em questão, ao entrar na universidade, interagissem, de algum modo, com as atividades do evento. Foi uma escolha política importante.

Dessa forma, mudou-se, pela primeira vez, a "cara do campus", pois incluíram-se, em um cenário que se propõe inclusivo, mas que é embranquecido e excludente, “coisas de preto": tecidos coloridos, imagens de orixás, plantas, poesias, músicas, tambores etc. Trouxemos para dentro do espaço do campus uma feira de produtos do As- 
sentamento Osvaldo de Oliveira, vinculado ao Movimento dos TrabaIhadores Rurais Sem Terra (MST); e inserimos na programação, além dos debates sobre saúde da população negra, a questão étnico-racial no Brasil; representantes de religiões de matriz africana discutindo o racismo religioso; e representantes da cultura afro-brasileira ocupando o espaço da universidade, com rodas de capoeira, samba e jongo (com o Jongo Tambores de Machadinha7), além de oficinas diversas, abertas a todos os interessados. Além da mudança estética, corpos negros da comunidade estavam dentro da universidade.

Observou-se, entretanto, que, com a realização do evento, uma intervenção em especial foi bastante significativa, pois aglutinou diferentes públicos e causou um impacto importante na comunidade universitária: o Desfile Afro. Essa ação ${ }^{8}$ reuniu alunos, professores e servidores terceirizados ${ }^{9}$ interagindo no mesmo espaço e ao mesmo tempo, sem hierarquizações. Foi marcante o impacto nos presentes, nos que desfilavam e nos que assistiram ao desfile, o qual, depois dessa primeira edição do projeto, tornou-se constante em todas as outras.

Uma mesa pequena colocada na entrada do saguão, onde os debates ocorriam, continha imagens de orixás e também foi marcante, mas por um motivo distinto: muitos reclamaram do teor religioso do evento, não entendendo que esse elemento tinha uma conotação de protesto e de chamar atenção para o racismo religioso a que são submetidos os praticantes de religiões de matriz africana. Foi possível presenciar alguns alunos dando a volta no saguão para não passarem em frente à "mesa de orixás". Durante a realização do evento, houve uma roda de oração (supostamente de neopentecostais) na entrada do campus, o que demonstra como a universidade é vista como um espaço embranquecido, segregado e racista.

Além disso, permite perceber o quanto ainda se deve avançar nesse debate. Atitudes como essas, tomadas dentro do espaço acadêmico, demonstram que o racismo se expressa de diferentes formas, inclusive travestido de "direito" religioso. 
Dessa forma, todas as edições da Semana de Cultura Afro-brasileira apresentam o debate em torno da questão étnico-racial e buscam valorizar a religiosidade, a estética e a cultura afro-brasileira, ação que se inicia pela decoração e pelo visual da universidade e converge para a realização de rodas de jongo, samba e capoeira dentro do campus. Sabe-se, no entanto, que a mudança de um espaço por meio de imagens, de cores e de objetos, por si só, não combate ao racismo e pode não impulsionar uma reflexão sobre outros aspectos dessas manifestações no país, mas o debate e a produção do conhecimento dentro da universidade devem estar aliados a intervenções que denunciem que o espaço e a estética também podem reforçar e facilitar opressões.

Como decorrência dessa proposta inicial, surgem projetos de pesquisa e extensão voltados à questão étnico-racial que se articulam, a partir de 2017, no Núcleo de estudos e pesquisas afro-brasileiro (Neab). Criaram-se também uma disciplina sobre esse tema, ofertada a estudantes de todos os cursos do campus, e pesquisas junto à comunidade quilombola do norte fluminense, além de outras ações que reforçam a indissociabilidade entre ensino, pesquisa e extensão.

\section{Ser negro na universidade: como me enxergo no que vejo e estudo?}

A representatividade tem sido usada como um conceito que remete à presença de negros em espaços até então negados pelo racismo estrutural e institucional. Apesar de ser um termo que se aplicaria, a priori, a qualquer espaço de poder, é na mídia, sem dúvida, que ele assume seu debate mais importante, posto que, no Brasil, esse meio, em particular, o televisivo, funciona como elemento criador de uma imagem distorcida da sociedade ou como uma projeção daquilo que devemos ser aos olhos de uma elite racista (SODRÉ, 1999).

Bell Hooks (2019) ressalta, na obra Olhares Negros: raça e representação, a dimensão política e revolucionária da desconstrução imagética de corpos negros racializados a partir do olhar do branco. Não se pretende aprofundar o conceito de representatividade, nem 
as armadilhas que ele contém. Indica-se apenas que, no tocante à questão negra, ele não diz respeito apenas a ter um ou mais negros na TV, no Senado ou em um comercial, por exemplo. Debater esse ponto é um compromisso epistêmico e ético (BORGES, 2019), pois há aí uma dimensão política que é atravessada pela luta de classes. Nesse sentido, alguns depoimentos apresentados neste item têm o objetivo de elucidar essa dimensão política da representatividade negra, explicitada a partir das ações do projeto de extensão Questões étnico-raciais e vivências em cultura afro-brasileira, especialmente durante a realização da Semana da Cultura Afro-brasileira no Campus da UFF em Rio das Ostras.

Além disso, não se pode negligenciar o quão é importante, para a construção identitária do negro brasileiro, ver-se representado nos livros de história, nos romances, nas poesias, nos cinemas e nas telenovelas, a partir de uma narrativa não racista, de uma história que não os coloque em um lugar de submissão e silenciamento. A representatividade faz parte do processo de construção identitária dos negros no Brasil e não pode ser negada nem menosprezada, mas implica questionar a branquitude, as opressões e a exploração de classe, além de denunciar e explicitar o racismo estrutural.

Para a mulher negra, só há representatividade quando ela deixa de ser vista, mostrada ou "vendida" como fetiche nacional, como a mulata, como a mulher boa de cama, "quente" e sambista (CONZALEZ, 2018). Qualquer elemento que reforce esse estereótipo machista e racista não implica representatividade, e questionar essa imagem requer a revisão das estruturas materiais que tornam essas mulheres as principais vítimas de feminicídio, de violência obstétrica e outras formas de violação. Não se trata aqui de um debate identitarista, que desconsidere a necessidade de transformação das estruturas sociais como forma de superar a sociedade capitalista e as formas diversas de opressão e exploração. Abaixo, observa-se um depoimento que corrobora com essa afırmativa. 
A Semana Afro, pra mim, é de longe um dos eventos mais importantes do Curo ${ }^{10}$. Estar próxima da minha ancestralidade, discutindo e construindo junto de semelhantes, traz um horizonte totalmente diferente para a minha vida. É riquíssimo ver a cultura da minha gente, do meu povo, tomar a universidade. Me sinto em casa. Em diversos momentos me emocionei, me arrepiei e cheguei a chorar, tamanha emoção que senti ao ouvir uma senhora falar sobre sua vida e sua ligação com as religiões de matriz africana. Ver um desfile de moda focado na beleza negra, com referências do povo preto, pra mim, foi maravilhoso. Trouxe paz pro meu coração. É uma iniciativa importantíssima, para lembrarmos de onde viemos e também para onde vamos. (Dandara", estudante da UFF. Depoimento sobre a Semana de Cultura Afro-Brasileira levantado junto ao projeto de extensão Questão étnico-racial e vivência em cultura afro-brasileira).

Na universidade ou mesmo em escolas, quando apenas se criam cenários imaginários que representem a cultura afro-brasileira, como eventos comemorativos alegóricos, sem que haja debate, problematização e mesmo pesquisa sobre a situação do negro no Brasil em seus aspectos sócio-históricos, políticos e culturais, não se contribui para o combate ao racismo. É possível o contrário, que se contribua para folclorizar a cultura em discussão. Dessa forma, entende-se que essas ações, atividades e eventos de extensão só cumprem o objetivo a que se propõem se, de fato, envolverem a comunidade, e, nesse caso, os movimentos sociais, culturais e de combate ao racismo em suas variadas formas. Tais movimentos são sujeitos e não objetos destas ações. Em relação à articulação com as vivências em quilombos, o depoimento a seguir é significativo:

O projeto de extensão Questões étnico-raciais e vivências em cultura afro-brasileira me proporcionou a ida e conhecer a vivência e dinâmica de um Quilombo. Esse movimento foi superimportante pelo fato de o projeto de extensão realmente seguir o seu objetivo, não ficar restrito na universidade e ir para além 
dela; essa troca de saberes da universidade com os quilombos e com as pessoas que vivem neles é essencial. É uma via de mão dupla! Para mim, enquanto estudante negro, foi muito marcante e emocionante ver e ouvir relatos dos quilombolas no que se refere ao período da escravização, o processo árduo (e burocrático) que é para a titulação dessas terras; terras estas que carregam toda uma história, todo um significado e ressignificado. Foi por meio desse projeto também que pude fechar o debate que eu irei levantar no meu TCC e que, com certeza, será a minha linha de pesquisa no mestrado e doutorado. Tenho certeza que projetos assim, além de nos darem uma outra percepção de mundo, de nos aproximar de debates que não conhecíamos, propicia também um crescimento enquanto ser humano, ainda quando se é uma pessoa negra, um sentimento de pertencimento ao estar nesses lugares, de ancestralidade e de sabermos que somos descendentes de pessoas que lutaram bravamente para o fim da escravização e permitiram eu estar aqui, na universidade, pautando as nossas questões e fazendo com que elas sejam legitimadas (Zumbi, estudante da UFF. Depoimento sobre a Semana de Cultura Afro-brasileira levantado junto ao projeto de extensão Questão étnico-racial e vivência em cultura afro-brasileira).

A realização de vivências em comunidades quilombolas também tem sido uma atividade bastante positiva do projeto aqui destacado. Há cinco anos, alunos e professores do campus participam da atividade cultural realizada no Quilombo São José, em Valença (RJ), em homenagem e comemoração ao dia de Preto Velho. Outras vivências são realizadas também no Quilombo Machadinha, em Quissamã (RJ), em datas comemorativas ou em debates sobre a realidade quilombola.

É importante problematizar a extensão com comunidades tradicionais (incluindo quilombolas) ou movimentos populares a partir de uma metodologia diferente da tradicional. Não se deve mais imaginar a extensão como ações pensadas e levadas para a comunidade, para grupos vulneráveis, de dentro para fora da universidade, de forma vertical e com pouco diálogo (BRANDÃO, 2013). Os sujeitos da extensão de- 
vem participar de suas diferentes etapas e contribuir com a construção, implementação e avaliação delas. Nesse sentido, metodologias participativas são essenciais (BRANDÃO, 2013).

O projeto se propõe, partindo da compreensão de que existe a necessidade de articulação coletiva protagonizada por pessoas negras, resistir ao modelo racista de sociedade que ainda existe no Brasil. As ações são pensadas de forma a promover integração entre diferentes pessoas, de faixas etárias distintas, bem como possibilitar a partilha de vivências e cultura. Para isso, são convidados para fazer parte dos eventos da Semana da Cultura Afro-brasileira estudantes da rede pública de ensino do município de Rio das Ostras, da modalidade regular e de Educação de Jovens e Adultos (EJA); mestres e praticantes de capoeira; moradores do Quilombo Machadinha, que trazem o jongo e suas vivências; moradores do assentamento Osvaldo de Oliveira, vinculados ao MST do município de Macaé; e grupos culturais afro-brasileiros locais.

Alguns projetos de extensão cumprem atualmente um papel essencial na universidade, pois permitem um contato direto e horizontal com a comunidade. No caso das Ciências Humanas e Sociais, esse contato é necessário e essencial em sua indissociabilidade com o ensino e a pesquisa. No depoimento a seguir, é possível observar o impacto de ações de extensão na criação ou construção identitária de mulheres negras trabalhadoras da universidade:

Eu era evangélica, era da Assembleia de Deus do Silas Malafaia, estava congregando lá e foi na época que comecei a me envolver mais com algumas atividades aqui, do campus. Comecei a me envolver mais com o sindicato administrativo da minha categoria, porque eu sou técnica administrativa aqui do campus, mas ainda era muito alienada, politicamente. Quem começou a me tirar desse processo de alienação foi a Semana Afro e tudo o que estava envolvendo a Semana Afro, por exemplo, tínhamos palestras, mesas-redondas falando sobre intolerância religiosa, algumas atividades extracurriculares, a disciplina de Questão Étnico-Racial, que falava sobre racismo. Mas tudo começou com 
o meu envolvimento com a Semana Afro. Teve um desfile, e eu participei e comecei a discutir política com outras pessoas que estavam envolvidas na Semana Afro, participei da disciplina e ali os meus olhos começaram a ser abertos. Tudo começou a me atrair a partir da pauta do racismo, porque principalmente nós, mulheres negras, a gente sente muito isso na pele, a gente não sabe por que acontecem certas coisas, porque a gente sempre é deixada de lado em uma balada, porque a gente sempre é deixada de lado em tudo, praticamente. Nós não somos sinônimos de beleza, nós somos totalmente o contrário do padrão de beleza atual, que é loiro, olhos azuis, mulheres esbeltas, e nós não somos nada disso. Então eu não entendia essas forças e hoje eu consigo compreender o porquê, porque isso acontece na nossa sociedade, porque o capitalismo sempre tenta manter o racismo, pois, sem racismo, não tem capitalismo, é uma maneira de oprimirem as pessoas negras. (Akotirene, técnica administrativa da UFF. Depoimento sobre a Semana de Cultura Afro-brasileira levantado junto ao projeto de extensão Questão étnico-racial e vivência em cultura afro-brasileira).

As ações que vêm sendo desenvolvidas no âmbito do projeto de extensão Questões étnico-raciais e vivências em cultura afro-brasileira têm fortalecido o protagonismo de docentes, discentes, técnicos-administrativos e outros trabalhadores, coletivos negros e movimentos sociais no âmbito da universidade e fora dela, na construção de uma educação antirracista, mas essas ações são apenas um instrumento dessa luta, que não pode ser pensada e implementada de forma isolada.

\section{Considerações finais: sementes da Semana de Cultura Afro-brasileira}

Se as cotas raciais mudaram o perfil dos estudantes nas universidades brasileiras, e os dados mostram que sim, o caminho para a construção de uma educação antirracista, que efetivamente seja crítica do lugar dos(as) negros(as), povos indígenas e outros grupos étnicos, como objeto ou problema, ainda é um percurso longo a ser feito e não se fará sem tensões e conflitos. A crítica epistêmica do(a) negro(a) 
como problema social não se dará sem o reconhecimento desses como sujeitos históricos dentro e fora do espaço acadêmico.

Atualmente o projeto de extensão Questões étnico-raciais e vivências em cultura afro-brasileira se articula com pesquisas sobre a questão racial e com a disciplina Questão étnico-racial ministrada pelos professores que coordenam essa extensão no Neab/UFF, reafırmando a indissociabilidade entre ensino, pesquisa e extensão na proposição de uma educação antirracista.

A Semana de Cultura Afro-brasileira tem se constituído como um evento científico e cultural importante para alunos, professores, técnicos administrativos e trabalhadores terceirizados negros, como um espaço de debates e resistência. Tem sido de vital importância para que os estudantes negros possam se identificar com o tema, construir articulações políticas e culturais e realizar trocas de conhecimento, além de compartilhar suas dores, dificuldades e conquistas.

A violência que atinge a população negra impacta sobre seus membros de forma coletiva. Esses espaços permitem que aqueles que ainda não tomaram consciência da dimensão disso possam fazê-lo e, consequentemente, unir-se com o objetivo de lutar para romper com o status quo, com um modelo de universidade branco e com uma estrutura de sociedade que perpetua o racismo. Após consecutivas realizações do evento e com a influência dele, que provocou mais amplamente o debate racial, foi criado, no ano de 2018, no campus aqui abordado, o Coletivo Negro Fuzuê, que reúne estudantes negros dos diferentes cursos do campus para pensar estratégias de fortalecimento e permanência na UFF, bem como realizar grupos de estudo para construção de acúmulo teórico sobre a questão racial. Alguns dos estudantes que participam diretamente da criação e organização do coletivo foram integrantes, e até bolsistas, do projeto de extensão apresentado neste artigo.

A partir dessas informações, é possível perceber uma forte influência da extensão na formação acadêmica dos estudantes da UFF, mas 
é necessário considerar ainda outros impulsionamentos promovidos, como um expressivo aumento no número de trabalhos de conclusão de curso produzidos na universidade após 2011 - primeiro ano de realização da Semana de Cultura Afro-brasileira - que tinham como objetivo debater a questão racial.

Todos esses exemplos constituem inegáveis influências da extensão para o debate racial e para a construção de uma sociedade antirracista. As universidades têm papel fundamental em contribuir para a elaboração de leituras reais da realidade brasileira, as quais possibilitem, de fato, a elaboração de políticas públicas, em especial, em épocas de predomínio de ideologias conservadoras, que questionem e modifiquem a realidade de opressões vividas por segmentos da população, como negros, mulheres e LGBTQI+. É, sobretudo, por meio da indissociabilidade entre ensino, pesquisa e extensão que as universidades públicas podem contribuir com a superação de opressões históricas e a transformação de realidades social e racialmente desiguais neste país.

\section{Referências}

ANDIFES. V Pesquisa do perfil socioeconômico e cultural dos estudantes de graduação das universidades federais. Brasília, 2019.

BOLETIM OCS N¹: Raça e Gênero nas Ciências Sociais: o perfil da pós-graduação no Brasil. Marcia Rangel Candido • João Feres Júnior • Luiz Augusto Campos, 2018. Disponível em: http://ocs.iesp.uerj.br/boletins/boletim1/. Acesso em: 21 set. 2020.

BORGES, Rosane. Das perspectivas que inauguram novas visadas. Prefácio. In: HOOKS, Bell. Olhares Negros: raça e representação. São Paulo: Elefante, 2009.

BRANDÃO, Carlos Rodrigues. Educação Popular e pesquisa participante: um falar algumas lembranças, alguns silêncios e algumas sugestões. In: STRECK, Danilo R., SOBOTTKA, Emil A., EGGERT, Edla. Conhecer e transformar: pesquisa ação e pesquisa participante em diálogo internacional. São Leopoldo: Oikos, 2013. 
BRASIL. Instituto Nacional de Estudos e Pesquisas Educacionais Anísio Teixeira (Inep). Censo da Educação Superior 2018: notas estatísticas. Brasília, 2019. Disponivel em: http://portal.inep.gov.br/informacao-da-publicacao/-/asset_publisher/6JYlsGMAMkW1/document/id/6734509. Acesso em: 21 set. 2020.

CARNEIRO, Sueli. Racismo, Sexismo e Desigualdade no Brasil. São Paulo: Selo Negro, 2011.

CERQUEIRA, Daniel. et al. Atlas da Violência 2019. IPEA, Fórum Brasileiro de Segurança Pública. Rio de Janeiro, 2019.

FANON, Franz. Pele negra, máscaras brancas. Tradução de Renato da Silveira. Salvador: EDUFBA, 2008.

GONÇALVES, Renata; AMBAR, Gabrielle. A questão racial, a universidade e a (in)consciência negra. Revista Lutas Sociais, n 34, jan/jun. 2015.

GONZALEZ, Lélia. Sexismo e racismo da cultura Brasileira. In: Primavera para as rosas negras: Lélia Gonzalez em primeira pessoa. Diáspora Africana, 2018. HOOKS, Bell. Olhares Negros: raça e representação. São Paulo, Elefante, 2009. NASCIMENTO, Abdias. O Genocídio do Negro Brasileiro: processo de um Racismo Mascarado. São Paulo: Perspectiva 2016.

QUIJANO, Aníbal. Colonialidade do poder, eurocentrismo e América Latina. In: LANDER, Edgardo (Comp.). La colonialidad del saber: eurocentrismo y ciencias sociales. Buenos Aires: Clacso, 2000.

RAMOS, Alberto Guerreiro. Introdução Crítica à sociologia brasileira. Rio de Janeiro: Editora UFRJ, 1995.

SANTOS, Antonio Bispo. Colonização, Quilombos: modos e significados. Brasília: 2015.

SILVA, Petronilha Beatriz Gonçalves. Negros na Universidade e produção de conhecimento. In: SILVA, Petronilha Beatriz Gonçalves; SILVERIO, Valter Roberto (Org.). Educação e ações afirmativas: entre a injustiça simbólica e a injustiça econômica. Brasília: Instituto Nacional de Estudos e Pesquisas Educacionais Anísio Teixeira, 2003.

SOARES, Maria. R. P. et al. Universidade pública e movimentos populares : aportes para o debate a partir da experiência do Programa de Extensão Assessoria Interdisciplinar em Saúde e Cidadania a Movimentos Populares. In: VIII Simpósio de Questão Agrária do NATRA : Movimentos sociais, Agroecologia e Soberania Alimentar. UNESP, Franca, 2018. 
SODRÉ, Muniz. A identidade como valor. In: SODRÉ, Muniz. Claros e escuros: identidade, povo e mídia no Brasil. Petrópolis, RJ: Vozes, 1999.

\section{Notas}

1 Doutora em Serviço Social pela Universidade Federal do Rio de Janeiro (UFRJ). Professora associada do Departamento Interdisciplinar da UFF/Campus Rio das Ostras. Brasil. Orcid: https://orcid.org/0000-0003-3360-7207. E.mail: raysoares2411@gmail.com

2 Estudante de graduação em Serviço Social pela UFF/Campus Rio das Ostras. Brasil. Orcid: https://orcid.org/0000-0003-4577-386X. E-mail: rebecaribeiro@id.uff.br

3 Dentro deste cenário de tensionamentos, há uma proposta em curso de destruição do caráter público e gratuito das universidades, sob uma perspectiva de mercantilização da educação superior. Reconhece-se que, em seu interior, há resistências quanto a essa concepção mercantilista da educação, e parte dessa resistência encontra-se ancorada em pesquisas e extensão produzidas dentro e a partir das universidades, em diálogo direto e horizontal com setores populares, periféricos e subalternizados da sociedade (SOARES et al., 2018, p. 537).

4 A pesquisa foi realizada a partir de uma consulta nas mídias sociais, em que os participantes de edições anteriores da Semana de Cultura Afro-Brasileira e/ou das visitas aos Quilombos de Machadinha (Quissamã/RJ) e São José (Valença/ RJ) foram convidados a dar um depoimento sobre suas experiências nesses eventos e a importância que estes exerceram. As considerações foram coletadas em entrevistas ou por meio de relatos escritos e depois expostos na atividade UFF nas Praças (as pessoas ouvidas concordaram, através de termo de compromisso, com a exposição de seus depoimentos e com a utilização neste artigo). Essa foi mais uma das iniciativas da Universidade, a partir da Pró-reitoria de Extensão, que teve como objetivo apresentar aos moradores das cidades onde a UFF possui campi os projetos de extensão desenvolvidos e sua importância, bem como divulgá-los e, consequentemente, fazer um convite para as futuras atividades da instituição.

5 Ao mesmo tempo em que aumentou o número de jovens negros nas universidades públicas, por meio das políticas afirmativas, no Brasil, atualmente, mais de $60 \%$ da população carcerária também é negra, assim como $75 \%$ das vítimas de homicídio. Como evidencia o Atlas da Violência 2019, de 2007 a 2017, a taxa de homicídios contra mulheres negras cresceu 29,9\%; enquanto, contra mulheres brancas, a taxa de crescimento foi de 1,6\% (CERQUEIRA, 2019).

6 Cabe aqui fazer referência a nomes de negros que romperam, mesmo que individualmente, com este ciclo (alguns de dentro e outros de fora do universo acadêmico), já nas décadas de 1970, 1980 e 1990, como Beatriz Nascimento, Abdias Nascimento, Guerreiro Ramos, Clóvis Moura, Lélia Gonzalez, dentre outros. 
7 O jongo é uma manifestação cultural afro-brasileira típica da região sudeste. Machadinha é um Quilombo localizado no município de Quissamã (RJ), onde desenvolvemos, com a comunidade, projetos de pesquisa e extensão.

8 Esta ação tem como idealizadora e organizadora uma produtora cultural, à época, estudante negra do curso de Produção Cultural, Marlúcia Soares.

9 Algumas servidoras negras terceirizadas relataram, posteriormente, que, ao desfilarem dentro da universidade e naquele evento, sentiram-se, pela primeira vez, como não invisíveis.

10 Centro Universitário de Rio das Ostras/UFF.

11 Todos os nomes dos depoimentos são fictícios. 